\title{
Evaluation of Investment Strategies in Iranian Stock Market
}

\author{
Mohammad E. Ezazi, Mostafa. Farrokhi Ostad, and Mojtaba. Farrokhi Ostad
}

\begin{abstract}
The main reason for studying investment strategies by financial experts is investor's inability to analyze the available information and lack of expertise in capital markets. Therefore researchers have classified investment strategies from different approaches. One of the most common categories that has been done on this classification, is passive strategies, active strategies and momentum investing. Each of these strategies can be divided into sub-strategies so this means that in advanced capital markets investors don't need to analyses and select their own stocks, but they need to specify their interest and Preferences which is determined through a specific questionnaire. This mater makes trading in Stock Exchange attractive and cause rational behavior of investors in the market. In This paper we have tried to examine concepts in four major hypotheses. Our Statistical sample is companies listed in Tehran Stock Exchange between (2006-2010). We excluded companies due to high financial leverage, damaging, low trading and inactive situation as well as investment companies. To study research's main and sub research hypothesis we used two independent-samples $T$ - Test to compare a sample. The Research conclusion indicated that performance of active and passive investment strategies in Tehran Stock Exchange have not any meaningful difference, although the average investment efficiency of passive investment strategies is more than active.
\end{abstract}

Index Terms-Active, Capital Market, Investing Strategy, passive, Performance.

\section{INTRODUCTION}

In recent decades, investment theories have followed an evolutionary track and achieved practical formulas. Historically, it can be stated that trade and investment have followed the "acceleration of history" theory: there has been a substantial increase in the amount of trade and investment in the present century; especially, in earlier years of this century, growth rates of trade and investment have accelerated, and the existing technologies and their near-future changes will no doubt affect the growth rates, amounts and conduct of trade and investment. These changes affect the criteria adopted for decision-making of investors (Islami Bidgoli \& Heibati 1375). Investment management consists of stock analysis and portfolio management. Stock analysis involves evaluating the benefits of each investment. But portfolio management involves analyzing investment

Manuscript received July 24, 2011; revised September 21, 2011

Dr.Mohammad E. Ezazi , Assistant Professor in the University of Sistan and Baluchestan, Iran.

Mostafa. Farrokhi Ostad, M.SC of Business Management, University of Sistan and Baluchestan, Iran (Corresponding author; Tel.:+989158196388 ; email: mostafafarokhy@gmail.com).

Mojtaba. Farrokhi Ostad, M.SC of Business Management, University of Sistan and Baluchestan , Iran (email: mojtabafarokhy@yahoo.com). mix and maintaining investment collections. In the recent decade, investment debates have shifted focus from the analytical selection strategies to portfolio management (Strong 2000: 3). Investment strategies are ways by which an investor can acquire the expected return, given a specified risk tolerance level. Extensive research has been done on the efficiency of investment strategies in most stock markets all over the world. The main reasons to study investment strategies on the part of the financial experts have been the lack of ability to analyze the capital market's data and the lack of appropriate expertise on the part of the investors (Fama and French, 1998).

Investment strategies have been classified according to very diverse views and approaches. One of the most popular classifications, around which most academic studies have been conducted, is the growth and value strategy. This strategy is part of the index-based investment strategy which belongs to the category of passive investment strategies (Jones, 2009).

In analyzing the common stocks investment strategies, active and passive approaches are treated quite independently. Investors can rely on these approaches when they attempt to select and mange their investment portfolios or select managers who would manage their portfolios on their behalf The active and passive approaches are adopted to satisfy different needs of investors, given their different risk-return tradeoff. Investment strategies are adopted at the levels of market, industry, and organization, which can serve as an appropriate guide for entering into and selecting investments more cognizant. Traditional emerging markets have developed rapidly over the past decades, both economically and financially.The topic of value and growth investing offers a shining example of the fruitful exchange of ideas between academic research and investment practice. The results from academic studies have formed the basis for investment strategies that are widely applied in equity markets. Going the other way, issues encountered by portfolio managers and consultants such as procedures for identifying value or growth styles, and the design of style-specific benchmark indexes for performance evaluation, have spurred ongoing analysis and extensions in the research literature (Katsenelson,2007).

The explosion of academic interest in value and growth investment strategies can be traced back to Fama and French (1992), and Lakonishok, Shleifer and Vishny (1994). The results of Fama and French delivered a stunning blow to the explanatory power of the Capital Asset Pricing Model, and sparked debates about the "death of beta." In the wake of this study, academics shifted their attention to the ratio of book-to-market value of equity, and firm size as the leading explanatory variables for the cross-section of average stock 
returns. In turn, this work built on earlier studies of stock market "anomalies." Basu (1977), for example, showed that stocks with low price-to-earnings ratios subsequently tend to have higher average returns than stocks with high ratios. Chan, Hamao and Lakonishok (1991) study Japanese data and find strong support for the superior performance of value investment strategies. Based on the accumulated weight of the evidence from studies on the book-to-market effect and related anomalies, the academic community has generally come to agree that value strategies on average outperform growth investment strategies. There is much less consensus, however, on the underlying reasons for the superior returns. On the one hand, Fama and French take the position of the efficient markets hypothesis, and attribute the higher returns of value strategies to their increased risk. On the other hand, Lakonishok, Shleifer and Vishny suggest that cognitive biases underlying investor behavior and the agency costs of professional investment management are at the root of the rewards to value investing. Yet another explanation for the returns to value investing rests on methodological issues of data selection bias (see Kothari, Shanken and Sloan). A careful study by Chan, Jegadeesh and Lakonishok (1995), however, suggests that any such bias cannot explain the differential performance of value and growth investing.

The academic work on value investing has had a strong impact on professional investment management. Value and growth are now widely recognized distinctive specializations adopted by money managers. Additionally, the research studies have been instrumental in the development of style-specific benchmarks which have proliferated in performance evaluation and attribution analysis. Many such benchmarks are based on a variable that has been extensively used in academic studies, namely the ratio of book to market value of equity, and this has become an important indicator of a portfolio's orientation toward either growth or value. This paper provides a review of the academic research on value and growth investing. We begin by surveying the evidence on the performance of value investment strategies. The underlying reasons for the performance are more controversial, so we also give an overview of the evidence on various explanations for the returns on value strategies. Finally we provide some updated evidence. The accurate assessment of the skill of fund managers is quite obviously of great value. It is also well known to be a very difficult task. A variety of techniques, some quite clever, have been devised. Some methods measure individual managers, others a class of managers. A few references are (Kosowski et al., 2001), (Muralidhar, 2001), (Engstrom, 2004), (Ding and Wermers, 2004). There are also (Ferson and Khang, 2002) and (Grinblatt and Titman, 1993).

\section{THE SIGNIFICANCE OF STUDY}

One of the most important achievements in the active stocks management in recent years have been investment strategies for the growth stocks, value stocks, selective stocks, and rotary stocks. In fact, it is a common fact that most managers of investment companies assign their portfolios 'active' or 'passive' labels.
So far, no comprehensive research have been conducted about the investment strategies adopted in Tehran stock market, the main reasons of which are the lack of information, the lack of familiarity with the investment strategies on the part of those involved in the capital market and the investors, and also the lack of appropriate criteria for each strategy. This study enables both natural and legal persons to adopt specific investment strategies based on the two basic factors in the capital management, risk and return, and decide more wisely about their investment opportunities.

\section{DEFINITION OF PORTFOlio MANAGEMENT}

\section{A. Common Stock Portfolio Management}

Portfolio theory allows investors to evaluate their expected risk and return. Harry Markowitz explained how to get at the right, or the best, asset combination in a portfolio, and proved that such portfolios are likely to be more successful (Shariat Panahi \& Jaffari 1389: 35). A portfolio is defined as a grouping of assets. Portfolio management consists of constructing portfolios and then making them evolve in order to reach the return objectives defined by the investor, while respecting the investor's constraints in terms of risk and asset allocation. The investment methods used to reach the objectives range from quantitative investment, which originated in modern portfolio theory, to more traditional methods of financial analysis. Quantitative investment techniques are now among the most widely used fund management methods. They are generally grouped into two major categories: active investment management and passive investment management, with the term "passive investment" covering both index investment and portfolio insurance. A general idea of the major trends in investment management is given below (Bohn and Stein, 2009, 16)

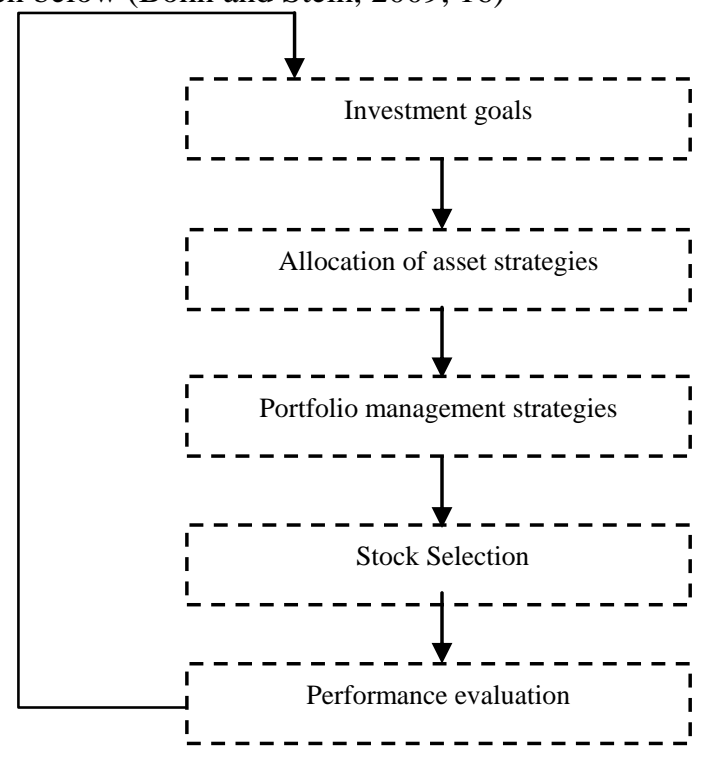

Fig.1. process of portfolio management (Raee and talangi, 2009, 107)

\section{B. Markowitz Model}

In 1950, Markowitz introduced the original portfolio model which provided a basis for the later Modern Portfolio Theory (MPT). Although investors were familiar with the concepts risk and return before Markowitz, they could not measure them. They already knew about the appropriateness 
of diversification. But, it was Markowitz who for the first time examined the concepts portfolio and diversification scientifically. He quantitatively showed that why and how a diversified portfolio can lead to a decrease in the portfolio risk (Liboutez et al. 2009: 74).

\section{Portfolio Management Process}

Before any stock trading, one must determine the investment policy, limitations of the expected return, risk tolerance, and other conditions upon which a portfolio should be formed. It is necessary to determine such factors on the part of investors before one selects stocks or determine an efficient portfolio combination .The following Figure1 is process of portfolio management (Raee and talangi, 2009, 107).In This study we have tried to survey on kind of investment strategies, which explain these concepts.

\section{Portfolio Formation}

Rational investors desire efficient portfolios, since such portfolios tend to maximize expected returns against fixed risk levels, or minimize risk for expected return levels (Strong: 2000: 4).

Having learned the basic financial principals, one need to form a portfolio, which presupposes that one familiarize oneself with the concepts and elements of capital market, the mathematical functions applied in the portfolio theory, and also with the concepts like portfolio risk and return and diversification (Conner et al. 2010: 54).

\section{E. Portfolio Management and Maintenance}

Having formed a portfolio, one need to set out to bring the portfolio up to date, and revise the expected goals of the portfolio. One can manage a portfolio actively or passively. Portfolio mangers need also to familiarize themselves with stock valuation principles (options, derivatives ...). They should also familiarize themselves with portfolio performance evaluation methods. What was stated above showed a general picture of portfolio management process in order to provide a theoretical framework. In this regard, researchers have developed other more practical approaches to portfolio management. The following figure illustrates the portfolio management decision-making process (Raee \& Talangi 1387: 107). This process, as shown in the figure, begins with determining investment goals. In this phase, the expected risk and risk tolerance of the investment are measured through investment statement summary. In the next phase, asset combination is determined which provides the best opportunity to get at the best return at the tolerated risk level, which is called assets allocation strategy: one constantly needs to change asset combination to achieve the best possible return. In the next phase, one needs to deal with the portfolio management strategies (active and passive) and stock selection which includes individual or group stock selections. The final phase of the stock portfolio management deals with the performance evaluation which acts as a feedback mechanism. This study focuses on stock portfolio management strategies, which are detailed below (Riley \& Brown 2002).

\section{F. Common Stock Portfolio Management Strategies}

Portfolio management strategies deal with two general categories: stocks and bonds. Since these strategies are frequently used in portfolio management, and since no bonds are available in Iran's capital market, this study deals with stock investment strategies. Stock portfolio management strategies are divided into two groups: active and passive strategies. Nowadays, new strategies have been added to these two, which are discussed as new strategies here (Dobbins et al.: 2005).

\section{G. Active Investment Strategies}

The objective of active investment management is to perform better than the market, or better than a benchmark that is chosen as a reference. Observation of financial markets shows that their theoretical efficiency is not perfect. They require a certain amount of time before they react to new information and asset prices are adjusted. As a result, there are short periods of time during which certain assets are not at their equilibrium value. Active investment management thus involves developing strategies to take advantage of temporary market inefficiencies. The choice of securities that will figure in the portfolio is an essential stage in this type of investment. The selection techniques are based on theoretical asset evaluation models, identifying the securities that should be purchased or sold, according to their upside or downside potential, which in turn is due to their under- or overvaluation by the market, with regard to the theoretical values proposed by the model(s) used. Portfolios that are actively managed contain fewer securities than those that are managed according to passive techniques, because detailed research into each security takes a considerable amount of time (Shenoy and Mccarthy, 2008)

It is also possible to practise active investment management at the asset class, rather than security, level (active asset allocation or tactical allocation). Funds that are managed through so-called "traditional" methods are also included in the area of active investment. These funds constitute a significant share of the funds that are available on the market. They are often relatively specialized. For the most part they use financial analysis, which consists of choosing each stock individually - the term used is "stock is picking" - based on research into the balance sheets and financial characteristics of companies (Lehmann, 2007, 64).

Although there is no general consensus over active management styles, but active strategies are usually divided into three groups as follows (Farrell 1998):

- Stock selection strategies;

- Sector Rotation strategies;

- Market Positioning strategies.

\section{H. Passive Investment Strategies:}

Passive investment management consists of tracking the market, without attempting to anticipate its evolution. It relies on the principle that financial markets are perfectly efficient, which means that financial markets immediately integrate all information liable to influence prices. It is therefore pointless to try to beat the market. The best technique in that case is to try to replicate a market index, i.e. invest in the same securities as those in the index in the same proportions. It has led to the creation of index funds, i.e. funds that are indexed on the market. These funds have the 
lowest management fees. Index investment allows an investor to have a diversified portfolio, without having to carry out research security by security. In addition, since the composition of indices is relatively stable, the turnover rate in the portfolios is relatively low, which limits transaction costs. Besides these classic index funds, funds called "tilted" index funds have been developed. These funds use a technique derived from that of classic index funds. The idea is to introduce an element of active investment, to try to obtain a performance that is better than that of the reference index, without exposing the portfolio to a market risk greater than that of the index. The goal is not to beat the index by a significant amount, but to beat it regularly. The difference in performance compared with the reference portfolio, measured by the tracking error is followed with precision and must remain within a relatively strict band. Management is based on analysis of the systematic portfolio risk, i.e. the share of risk that is not eliminated by diversification. The risk is broken down with the help of multi-factor models. These models allow the different sources of risk to be analyzed and the portfolio oriented towards the most lucrative risk factors, which allows the tilt sought to be obtained. The index can also be tilted using more traditional methods, with a financial analysis-based stock picking strategy. The multi-factor analysis then guarantees that stock picking has not modified the overall exposure of the portfolio compared with that of the index. In certain cases a portfolio composition constraint is imposed by reducing the stock picking to a simple over or underweighting of the stocks that make up the reference index (Katsenelson, 2007).

Passive strategies, unlike active strategies which focus on the achievement of excess returns out of market fluctuations, focus on the long term performance of a specific part of capital market. In other words, a passive portfolio is one that is maintained because of the lack of ability to predict. A passive portfolio aims to bring the portfolio return as close to the index to which it is benchmarked as possible. According to Oudin \& Barber (2000: 773), there are two kinds of passive strategies:

- Buy and hold strategy;

- Index investment strategy.

\section{Momentum investing}

The asset allocation decision is fundamental in the determination of the portfolio composition for a fund manager. Once an active investment manager has set their strategic or long-term benchmark weight across multiple asset classes, the tactical allocation decision requires the manager to vary the overall exposure to individual assets classes (e.g. Australian and International Equities, Cash, Australian and International Fixed Interest, Property) as a means of enhancing the overall performance of the fund. Aggregate fund performance is both a function of passive and active asset allocation inputs. Passive changes in asset allocation occur when high (low) returns on an individual asset class results in an increase (decrease) in the weight of that class as a proportion of total fund assets. Given the importance of tracking error constraints, managers will be required to rebalance their portfolios in a manner which ensures any differential performance between asset classes does not compromise the overall investment strategy adopted by the fund. Active changes occur when the manager moves funds from one asset class to another with respect to expectations about future returns. These active changes are referred to as tactical asset allocation. The importance of the asset allocation decision has been examined by Brinson, Hood and Beebower (1986), Brinson, Singer and Beebower (1991) and Ibbotson and Kaplan (2000). These studies show that more than 90 per cent of the variation in fund performance is explained by a fund's asset allocation decision. Blake, Lehmann and Timmerman (1999) and Faff, Gallagher and $\mathrm{Wu}$ (2004) examine the dynamics of the tactical asset allocation decision in multiple asset funds in the UK and Australia, respectively. These studies find that, even though active fund managers do engage in tactical asset allocation strategies, they are unable to provide superior returns for investors. Diversified funds would 3 generate higher returns by following a passive asset allocation policy rather than employing an active asset allocation strategy (Leibowitz,2009,402).

The skill and motivation of the fund manager in implementing active strategies have also been examined in the literature. There is a vast body of research examining the selectivity and timing abilities of funds managers, (see for example: Treynor and Mazuy, 1966; Kon, 1983; Henriksson, 1984; Chang and Lewellen, 1984; Lee and Rahman, 1990; and in the Australian context Sinclair, 1990; Gallagher, 2001; and Hallahan and Faff, 2001). More recently, behavioural theories have provided insight into fund manager activities. Brown, Harlow and Starks (1996) hypothesise that managers seek to increase the risk and returns of heir fund portfolio after a poor performing period. They view the industry as a tournament between the participants, where interim losers increase their portfolio risk as a means of enhancing performance. Wermers (1999) examines the herding behavior of fund managers and shows that managers do follow one another into and out of the same securities. Grinblatt et al. (1995) and Burch and Swaminathan (2001) show institutional investors engage in buying stocks with high past returns. This behaviour is consistent with momentum investing. Bange and Miller (2004) examine momentum investing in the context of global asset allocation recommendations of investment houses, and find evidence to support the application of momentum investing in equity and cash allocation decisions.

The concept of momentum investing with respect to stock selection has had considerable attention in the literature. However, research on the application of momentum investing to asset classes and the asset allocation decision is limited. In this paper we assess how momentum investment strategies are employed by fund managers in their tactical asset 4 allocation decisions. Specifically, we examine if historical returns of asset classes are a determinant of the amount invested in the key asset classes that comprise a multiple asset class managed fund. We focus on momentum investing as one possible explanation of the fund manager's asset allocation decision, and hence contribute to the behavioral research of assessing fund managers' strategies. The examination is undertaken using a proprietary dataset of the strategic and tactical asset allocation components of fund 
managers' asset allocation activities in Australia. Further, we extend the concept of momentum investing from stock selection to asset class allocation.

\section{DATA AND Methodology}

\section{A. Data}

The data is sourced from the RAHAVARD NOVIN database provided by TADBIR PARDAZ Investment Consulting (MIC). The sample period is January 2006 to December 2010. The number of sample is 124 .

\section{B. Methodology}

(Population, samples, and sampling methods)

The population consists of all the companies involved in Tehran stock market. The time interval is from 1384 of the Iranian Calendar/2006 of the Gregorian calendar to 1388 of the Iranian Calendar/2010 of the Gregorian calendar.

The sampling method is judgmental. Since the sample (the whole population) should be consistent with some variables, the methods used in previous studies have been applied. The following methodology has been used for sampling:

1) Companies which were closed down more than 3 consecutive months in a single financial year.

2) Companies suffering from losses.

3) Financial intermediaries (the reason why financial institutions are not selected is their high leverage ratios, which it is not necessarily indicative of their financial weakness). Fama and French (1992) excluded the financial institutions from their samples by the same reason. They believe that high leverage ratios are common for financial institutions, but it means something else to non-financial institutions, which puts these institutions under stress.

4) Companies with no stocks transactions within the last three months or so.

5) Companies whose financial year has not ended in the late Esfand were excluded from the chosen sample. The number of eligible companies was 183 in 1384 and 173 in 1388 .

\section{Research Variables and their Calculation}

For explanation and comparison of different investment strategies adopted in Tehran stock market, the following criteria were used:

1) The following criteria which can affect determining all kinds of growth and value strategies were applied: the ratios $\mathrm{BV} / \mathrm{MV}, \mathrm{E} / \mathrm{P}, \mathrm{CF} / \mathrm{P}$, and D/P. Since the first two criteria are less affected by the Management, they are regarded as the constant ratios in this study. BV/MV (book value-to-market value ratio), and $\mathrm{E} / \mathrm{P}$ (earnings-to-price ratio) were used for determining growth and value investment strategies.

2) The intrinsic value, which the price is taken in the last day of the time period under investigation. Also, the tendency of market price of a stock to move towards its intrinsic value determined the selective investment strategy.

3) The expected return was seen as a measuring stone to determine the rotary stocks in Tehran stock market. It is worth noting that every asset has two kinds of return: the expected return, the realized return. In order to determine the rotary investment strategy, we needed to determine all likely earnings; therefore, the expected return was taken into account.

Insert figure 2: Conceptual model components

\section{RESUlts}

\section{A. Descriptive Statistics}

Descriptive statistics are presented in Table 1.

TABLE 1: TEST OF MAJOR HYPOTHESES

\begin{tabular}{|c|c|c|c|c|c|c|c|}
\hline \multirow[t]{2}{*}{ Hypotheses } & \multicolumn{5}{|c|}{ Sig } & \multirow[t]{2}{*}{ df } & \multirow[t]{2}{*}{ Results } \\
\hline & 2006 & 2007 & 2008 & 2009 & 2010 & & \\
\hline Major1 & & & & & & & accept \\
\hline Subsidiary1 & .001 & .001 & .005 & .141 & .001 & 122 & accept \\
\hline Subsidiary2 & .001 & .014 & .019 & .0709 & .013 & 40 & accept \\
\hline Subsidiary3 & .001 & .031 & .035 & .036 & .001 & 82 & accept \\
\hline Major2 & & & & & & & Not recognized \\
\hline Subsidiary4 & .160 & .042 & .049 & .024 & .001 & 40 & accept \\
\hline Subsidiary5 & .001 & .546 & .085 & .004 & .372 & 53 & conpentswreject \\
\hline Subsidiary6 & .048 & .001 & .001 & .002 & .003 & 122 & accept \\
\hline Subsidiary7 & .001 & .146 & .731 & .647 & .030 & 92 & reject \\
\hline Major3 & & & & & & & reject \\
\hline Subsidiary8 & .0127 & .001 & .022 & .257 & .006 & 80 & accept \\
\hline Subsidiary9 & .350 & .195 & .014 & .147 & .363 & 93 & reject \\
\hline Subsidiary10 & .003 & .813 & .875 & .955 & .169 & 121 & reject \\
\hline Subsidiary11 & .001 & .075 & .816 & .617 & .029 & 122 & reject \\
\hline Major4 & .004 & .101 & .044 & .0190 & .554 & 16 & accept \\
\hline
\end{tabular}




\section{CONCLUSIONS}

The findings from the Main Hypothesis I:

With respect to the findings from the secondary hypotheses, one can conclude that the main hypothesis I, which indicates that the growth investment strategy performs better than the value investment strategy in Tehran stock market, is acceptable in all the years from the time period under investigation except for 1387. This fact is further illustrated in the tables of the secondary hypotheses and the mean values of these strategies and by the market return mean values. These findings reiterate those of shavakhizavare (1382-1378), but they are against those of Chan \& Lockinshoc $(2000,2004)$ and Fama and French (1998).

The findings from the Main Hypothesis II

With respect to the findings from the secondary hypotheses considered here, one can possibly conclude that the selective investment strategy yields a higher and more significant return than the mean market return; but the rotary investment strategy yields an above mean return. This difference is not significant. But it can be said that the rotary investment strategy yields more profit than expected in the short run compared to the other given strategies. Finally, it can be concluded that based on all the findings from the secondary hypotheses, there is no significant difference between the selective investment strategy and the rotary investment strategy adopted in Tehran stock market. The findings from the secondary hypothesis IV indicates that the selective investment strategy yields a lower return than the mean market return. It is against the findings from Achour et al. (1998), van der Hart et al. (2005), and Craigheadet al. (2001) which showed a higher significant return than the mean market return in the newly born markets. Also, the finding from the secondary hypothesis $\mathrm{V}$ indicates that there is no significant difference between the rotary investment strategy return and the mean market return; in other words, this strategy yields a return close to that of the mean market return. This finding is in line with those of Li.Eric (2004), Stangl et al. (2007), and Kampen (2010).

The findings from the Main Hypothesis III

Therefore, with respect to the secondary hypotheses VIII and IX, we can possibly conclude that the growth investment strategy yields a higher return than the selective investment strategy, but is not significantly different from the rotary investment strategy. It can be concluded from the secondary hypotheses X and XI that while there is no significant difference between the value investment strategy return (as a passive strategy) and the selective and rotary investment strategies returns (as active strategies), but by comparison of different strategies' mean returns, it can said that the active strategies perform better than value strategies. Finally, by analyzing the secondary hypotheses resulting from the main hypothesis III, it can be said with $95 \%$ certainty that (of course taking the approval of the secondary hypothesis VIII) there is no significant difference between the active and passive investment strategies' returns in Tehran stock market.

The findings from the Main Hypothesis IV

With peruse means of returns this strategy in the confirmed years, we find that often been more appropriate the performance of price movement trend then mean of market return; Of course are not visible, this trend in the initial and final years scrutinized time confine, that reduce of generalizable discussions to aimed society.

According to the original assumption of investment is based on the moving trend, if the stock has higher performance during the past few periods than the market performance, this trend will continue likely. Of course, we must know that investment based on movement trend is reckoning short term approach. Finally can say that use this strategy will offer in the Iranian stock exchange (ISE) at short term over of mean of market performance probably, although was not significant this difference. Therefore, the performance of this strategy will be over of mean of market performance in Tehran Stock Exchange (TSE) probably. That this result, based on research findings of Fadaee Nejhad and Sadeghi (2009), DeBount and Taller (1987) and Tony and others (2008), which has been reported extra return for movement trend strategies in the short term.

\section{SUGGESTIONS}

In this section, some suggestions are made based on both the research hypotheses and general issues.

\section{A. Suggestions based on the Main Hypothesis I}

With respect to the findings from the secondary hypotheses and also the main hypothesis I, both natural and legal investors can adopt the growth investment strategies in Tehran stock market if they think that the passive investment strategies tally with their ideas about risk and return, and want to perform better than the market.

\section{B. Suggestions based on the Main Hypothesis II}

With respect to the findings from the secondary hypotheses and also the main hypothesis II, both natural and legal investors can adopt the selective investment strategies in Tehran stock market if they think that the active investment strategies tally with their ideas about risk and return, and want to perform better than the market.

\section{Suggestions based on the Main Hypothesis III}

With respect to the findings from the secondary hypotheses and also the main hypothesis III, both natural and legal investors can adopt the rotary investment strategies in Tehran stock market if they want to perform as equally good as the market.

\section{Suggestions based on the Main Hypothesis IV}

According to the results of the fourth main hypothesis, suggest to natural and legal investors that if know the new investment strategies based on risk and return their thinking and following achieve to performance more than of market performance, of course, use in short-term confines of investment strategy of price movement trend in Tehran Stock Exchange(TSE)

General and Operational Suggestions

With respect to the research hypotheses and the previous studies, the following suggestions are made: 
- It is necessary to take steps to familiarize people with the investment strategies adopted in Tehran stock market. Therefore, the authorities are advised to hold educational courses (in the elementary, intermediate, advanced levels) for familiarizing both the natural and legal investors with the subject.

- Authorities are advised to emphasize the more rational and reasonable investment mechanisms especially those which valuate this market as it absorbs the financial assets of the country.

- The investment managers and/ or the professional investors should base their investment strategies on the two main decision-making criteria in the financial markets, risk and return, and also on the investment timing, and the financial stability.

- Important indices should be ascertained to identify companies which adopt different investment strategies in Tehran stock market.

- Determining indices should be ascertained to identify different investment strategies adopted in Tehran stock market.

\section{APPENDIX}

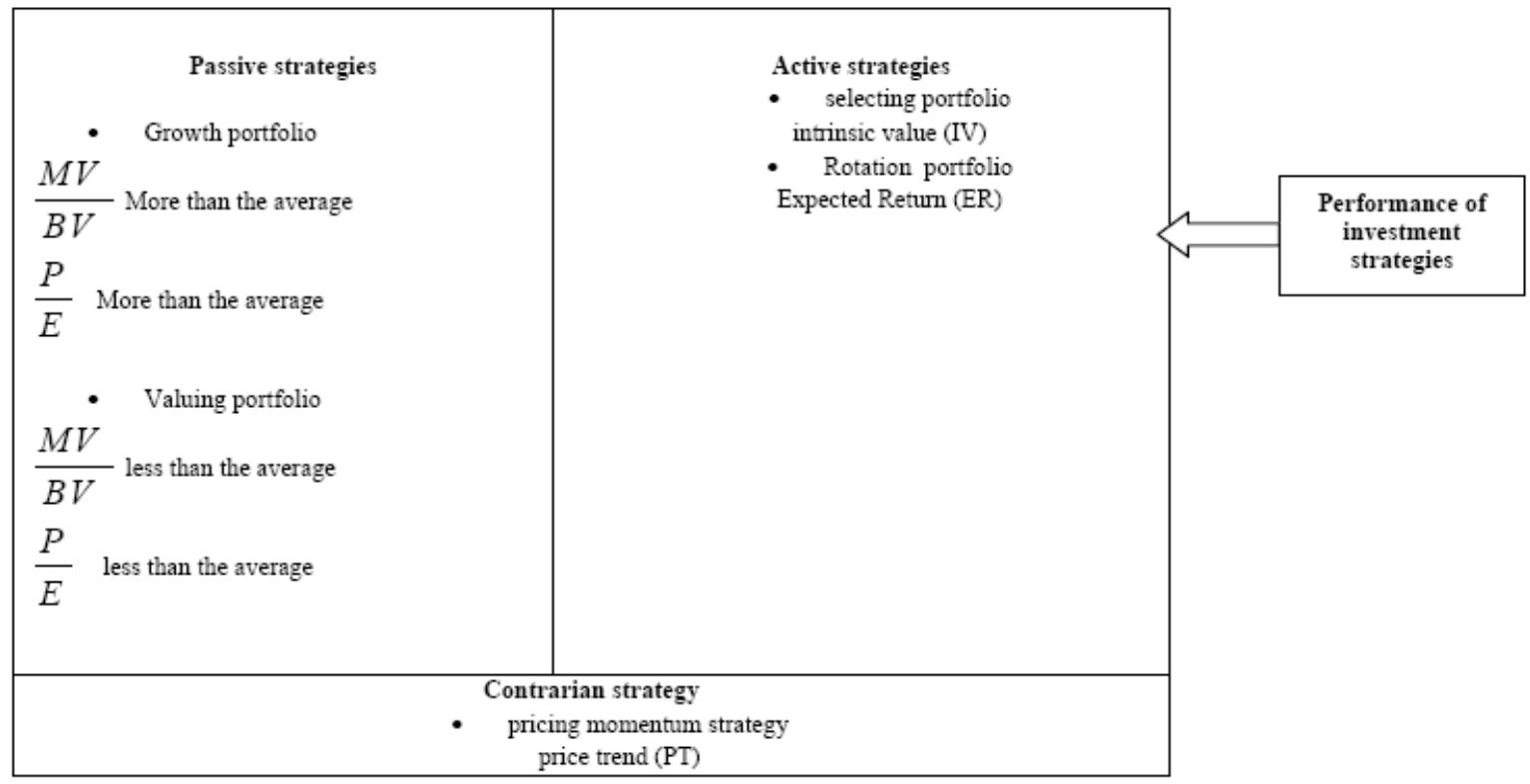

Fig.2. Conceptual model Components

\section{REFERENCES}

[1] Fuller Russell.j and james 1. Farrell,(1987),"Modern Investments and Security Analysis", Mcgraw-Hill.

[2] Neveu, Raymond p.,(1989),"Fundamentals of Managerial Finance",3red ed,Cincinnati,ohio,south-western Publishing co.

[3] Fama, E.F., French. K.R, (1992), "The Cross-section of expected Stock Returns", Journal of Finance 47, 427-465.

[4] Fama.E.F., French. K.R,(1995),"Size and Book - to - Market factors in emerging and returns", Journal of Finance 50, 131,155.

[5] Eslami bidgoli, gholamreza and Farshad heibati,(1996),"Portfolio Management with use by Index Model", Tahghighat mali journal.

[6] Fama.E.F., French. K.R, (1998),"Value versus growth: the international evidence", Journal of Finance 53, 1975-1999.

[7] Grinblantt.M., Moskowitz.T.,(1999),“Does industry explain momentum?", Journal of Finance 54, PP.1212-1249.

[8] Strong,Robert A.,(2000),"Portfolio Construction, Management \& Protection",2d.ed,South Western Callege.

[9] Haugen,Robert A.,(2001),"Modern investment theory",5th ed,Upper Saddle River, NJ ; [Great Britain] : Prentice,Hall.

[10] Jegadeesh.N. Titman.S.,(2001),"Profitability of momentum strategies: an evaluation of alternative explanations", Journal of Finance 56, 699-720.

[11] Amenc, Noel and Veronique le sourd,(2003)," Portfolio Theory and Performance Analysis", John Wiley \& Sons Ltd, The Atrium, Southern Gate, Chichester, West Sussex PO19 8SQ, England.
[12] Chan,Pui-Kit, Wai-Ki Ching, Siu-Pang Yung,(2003),"Optimal strategies in equity securities and derivatives", Elsevier Inc.

[13] Hon,M.T., Tonks.I,(2003), "Momentum in the UK stock market", Journal of Multinational Financial Management 13 (1), PP. 43-70.

[14] Fabozzi j. Frank, Sergio. Focardi, petter N. kolm, (2006),"Financial Modeling of the Equity Market", new jersy, wiley.

[15] Stangl, Jeffrey, , Ben Jacobsen, Nuttawat Visaltanachoti,(2006)," Sector Rotation over Business-Cycles", North Shore Mail Centre, Auckland, New Zealand.

[16] Fabozzi, Frank J. , et al,(2007),"Robust portfolio optimization and management",New jersy,wily\& sons.

[17] Katsenelson, Vitaliy, N.,(2007),"Active Value Investing ”, John Wiley \& Sons, Inc., Hoboken, New Jersey.

[18] Lehmann, Richard,(2007),"Incom investing tody", John Wiley \& Sons, Inc., Hoboken, New Jersey.

[19] Bodie, Z., A. Kane, and A.J. Marcus, (2008)," Essentials of Investments", 7th ed., McGraw-Hill/Irwin.

[20] Shenoy Catherine, Kent C. Mccarthy, (2008),"Applied Portfolio Management ", John Wiley \& Sons, Inc., Hoboken, New Jersey.

[21] Tony, Naughton, Cameron Truong, Madhu Veeraraghavan,(2008),"Momentum strategies and stock returns:Chinese evidence", Pacific-Basin Finance Journal, N.16 , 476-492.

[22] Jones,ChaelesP.,(2009),"Investment Analysis and Management", $5 \mathrm{~d}$,John Wiley \& Sons.

[23] Leibwitz, Martin L,et al,(2009)," Modern Portfolio Management", John Wiley \& Sons, Inc., Hoboken, New Jersey. 
[24] Raei,Reza and Ahmad Talangi,(2009),"Advanced Investment Management",2red edu,Tehran,Samt publishing.

[25] Bohn, Jeffrey R. And Roger M. Stein,(2009),"Active Credit Portfolio Management in Practice", John Wiley \& Sons, Inc., Hoboken, New Jersey.

[26] Connor, Gregory,et al,(2010),"Portfolio Risk Analysis", Princeton University Press, 41 William Street, Princeton, New Jersey 08540.

[27] Haslem, John A., (2010),"Mutual Funds:Portfolio Structures, Analysis, Management, and Stewardship ”, John Wiley \& Sons, Inc., Hoboken, New Jersey.

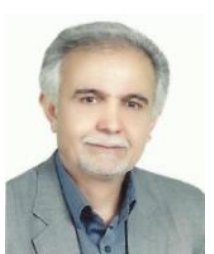

Mohammad Esmaeil. Ezazi, Assistant Professor, university of Sistan \& Baluchestan,Iran. BA, in Economics, Ghazvin,Iran. M.B.A, in Accounting \& Management Technology, Northrop,USA. Ph.D, in Financial Management.Tehran,Iran. And his Interest areas of study are Capita Market, Investment, Financial Decision Making and Corporate finance.

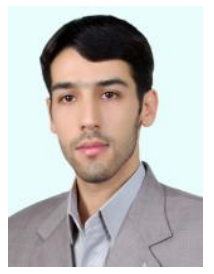

Mostafa Farrokhi Ostad was born in Mashhad city, Iran; in 1984. He graduate business management from Semnan university of Iran in 2007 (Undergraduate) and he obtained graduate degree (MSc) in finance field from Sistan \& Baluchestan university of Iran in 2009. $\mathrm{He}$ teaches finance \& entrepreneurship issues in business plan (B.P). And teaches issues in management and accounting field. Research interest is the field behavior finance and eco-finance. He have more than ten published articles in the finance and accounting area. (Investment strategy, public and private ownership, privatization, earning quality, funding method, IPOs, internal and external investment)

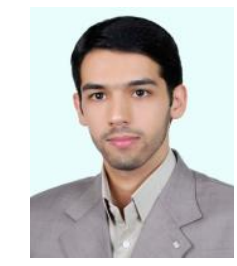

Mojtaba Farrokhi Ostad was born in Mashhad city, Iran; in 1984. He graduate business management from Ferdowsi university of Iran in 2007 (Undergraduate) and he obtained graduate degree (MSc) in finance field from Sistan \& Baluchestan university of Iran in 2009.

He teaches finance \& entrepreneurship issues in business plan (B.P). And teaches issues in management and accounting field. Research interest is the field behavior finance and eco-finance. He have more than ten published articles in the finance and accounting area. (Investment strategy, public and private ownership, privatization, earning quality, funding method, IPOs, internal and external investment) 